\title{
The Influence of Non-framework Sodium Cations on the Adsorption of Alkanes in MFI- and MOR-Type Zeolites
}

\author{
Edith Beerdsen, Berend Smit, and Sofía Calero* \\ Department of Chemical Engineering, University of Amsterdam, Nieuwe Achtergracht 166, \\ 1018 WV Amsterdam, The Netherlands
}

Received: June 7, 2002; In Final Form: August 2, 2002

\begin{abstract}
Molecular simulations were performed for the adsorption of methane, ethane, and propane in MFI- and MORtype zeolites with various nonframework sodium and framework aluminum densities. The position of the nonframework sodium cations determined by Monte Carlo simulations is in agreement with positions determined by X-ray diffraction. The position and density of the sodium and aluminum atoms in the zeolite have a large influence on the adsorption of alkanes. The computed adsorption isotherms and Henry coefficients agree well with those obtained experimentally. Finally, we show that Configurational Bias Monte Carlo (CBMC) simulations are able to provide a better understanding of the effect of nonframework sodium on the selective adsorption of binary mixtures of isomers by these structures. Our results show that increasing the nonframework sodium density in MFI-type zeolites increasingly blocks the intersections and thereby increases the selectivity of MFI-type zeolites for adsorbing linear alkanes. By contrast, increasing the nonframework sodium density in MOR-type zeolites increases the number of sites favorable for adsorbing small linear alkanes.
\end{abstract}

\section{Introduction}

Crystalline silica can be synthesized with many different nanoporous structures. These silicas become catalytically active zeolites by substitution of trivalent aluminum for tetravalent silicon into the silica framework. Each substitution creates a net negative charge in the framework, which is compensated by a cation. The location of these cations influences the adsorption and the catalytic properties of the materials. ${ }^{1}$ Although crystalline silica structures are well defined, the introduction of aluminum induces chemical disorder. The problem of characterizing this disorder has not yet been solved in general. This requires a detailed microscopic description of the distribution of the $\mathrm{Al}$ atoms in the zeolite framework for the different $\mathrm{Si} / \mathrm{Al}$ ratios, which is difficult to extract from the available experimental data. The atomic scattering factors of $\mathrm{Si}$ and $\mathrm{Al}$ are too close in X-ray diffraction. Therefore, the discrimination of the chemical nature of the tetrahedral atoms ( $\mathrm{Si}$ and $\mathrm{Al}$ ) can only be obtained indirectly by considering the slight difference between the $\mathrm{Si}-\mathrm{O}$ and $\mathrm{Al}-\mathrm{O}$ bond lengths and the $\mathrm{Si}-\mathrm{O}-\mathrm{Si}$ and $\mathrm{Al}-\mathrm{O}-\mathrm{Si}$ angles.

In the last years, molecular simulations have played an important role in developing our understanding of the relation between microscopic and macroscopic properties of confined molecular fluids in zeolites. In particular, Monte Carlo simulations are capable of accurately predicting adsorption isotherms of linear and branched hydrocarbons ${ }^{2-6}$ and mixtures of alkanes 7,8 in zeolites. An understanding of the adsorption properties of these materials can be helpful to explain the underlying mechanisms of processes such as catalytic cracking or hydroisomerization of hydrocarbon molecules, as well as to identify further applications of zeolites as catalysts and adsor-

* Corresponding author. Fax: (+31) 20525 5604. E-mail: calero@ science.uva.nl. bents. Most of these simulations focus on the all-silica form; the influence of the $\mathrm{Si} / \mathrm{Al}$ ratio on these properties is therefore far less understood.

In this work we have considered two different types of structures: Mordenite (MOR topology), and ZSM-5 (MFI topology). MOR exists in a large $\mathrm{Si} / \mathrm{Al}$ ratio domain and therefore is a particularly useful zeolite for several catalytic applications. The structure with the highest $\mathrm{Al}$ content has a composition of $\mathrm{Na}_{8} \mathrm{Al}_{8} \mathrm{Si}_{40} \mathrm{O}_{96} \cdot n \mathrm{H}_{2} \mathrm{O}$ and the structure can be refined with $\mathrm{Cmcm}$ symmetry. ${ }^{9}$ The framework has a porous structure, which consists of main channels parallel to [001], having a slightly elliptical cross section with $12 \mathrm{TO}_{4}$ tetrahedron units $(\mathrm{T}=\mathrm{Si}, \mathrm{Al})$, which are connected with small side channels parallel to [010], with $8 \mathrm{TO}_{4}$ cross sections called side-pockets. Zeolites with medium pore sizes, such as MFI are useful for separation processes since the sizes and shapes of the channels affect the rates at which adsorbates diffuse. This zeolite is one of the industrially most important structures ${ }^{10,11}$ and it can be synthesized with a framework composition range $8 \leq \mathrm{Si} / \mathrm{Al} \leq$ $\infty$. MFI-type zeolite ${ }^{12}$ is characterized by a three-dimensional pore system with straight, parallel channels intersected by zigzag channels. Around room temperature, this zeolite typically has an orthorhombic symmetry (space group Pnma) with 12 distinct crystallographic T-sites with equal populations. ${ }^{13}$

The adsorption capacity of the zeolites is known to vary with both the zeolite type and the nonframework cation distribution. ${ }^{14}$ In MOR, highly nonideal adsorption behavior was observed for smaller (methane and ethane) alkanes. This nonideality is due to the two distinct adsorption sites existing in the zeolite. The side pockets are accessible only to small molecules, whereas larger hydrocarbons can only access the main channels. ${ }^{15}$ Moreover, previous experimental ${ }^{16,17}$ and molecular simulation ${ }^{18}$ results on adsorption of alkanes in MOR indicate that for all adsorbates decreasing the nonframework cation density (by 
increasing the framework $\mathrm{Si} / \mathrm{Al}$ ratio) decreases the loading at a given pressure. ${ }^{19}$ In contrast, MFI shows the opposite behavior: decreasing the nonframework cation density inside MFI-type pores (slightly) increases the loading.

The separation of alkane mixtures is usually achieved by selective adsorption by zeolitic materials. ${ }^{3,20,21}$ Zeolites with high separation selectivities for molecules of different size and shape are particularly useful, for they afford the separation of mixtures of isomers. ${ }^{22-25}$ The adsorption selectivity of a mixture of isomers depends on the zeolite structure and the type, density, and location of nonframework cations. In MOR, consisting of straight cylindrical channels, length entropy favors the branched alkane at high mixture loading. In MFI, consisting of intersecting channel structures of medium pore size, configurational entropy favors the linear isomer. ${ }^{25}$ Moreover, the linear/branched separation selectivities increase with increasing nonframework cation density inside MFI-type channels. ${ }^{26}$ Finally, another factor of interest in adsorption selectivity is the temperature. For purely siliceous MFI, the $n$-butane/isobutane separation selectivity decreases with increasing temperature..$^{23,27}$ In the presence of nonframework cations it increases with increasing temperature and has a maximum at a certain temperature. ${ }^{26,28}$

The aim of this work is 2-fold. First we study the effect of charges in the crystal structure, cation locations, and cation loading on adsorption properties of alkanes in MOR- and MFItype zeolites. Subsequently, we use this information to obtain a better understanding of the influence of nonframework sodium cations in the selective adsorption of binary mixtures of $\mathrm{C}_{4^{-}}$ isomers in these structures. The remainder of the paper is organized as follows: in Section 2 we present our simulation methods, including descriptions of the force fields used in this work. We continue in Section 3 with the results of our simulations. These include adsorption isotherms and selectivity studies. Finally, in Section 4 we give some concluding remarks.

\section{Computational Methods}

For the first part of our study and to analyze the influence of $\mathrm{Al}$ in the adsorption of small alkanes, we performed molecular simulations of methane, ethane, and propane in MOR- and MFItype zeolites. These three alkanes were chosen as adsorbates because their structural simplicity enables us to give a straightforward interpretation for the role that cation location and zeolite structure play in adsorption properties. Moreover, methane and ethane are small enough to access all the micropores of NaMOR. For the second part of our study equimolar mixtures of butane and isobutane have been considered. Since in general any mixture of isomers can be used to study adsorption selectivity, we use these small isomers because they are efficient from a computational point of view. Further advantage is the availability of experimental and simulation data for comparison. ${ }^{16-19,23,26,28}$

2.1. Zeolite Models. Three MOR and six MFI unit cell compositions were modeled. MOR-type sieves were made with 0,5 , and 8 sodium (and aluminum) atoms per unit cell of in total 48 silicon and aluminum atoms, MFI-type sieves were made with $0,2,3,5,6$, and 8 sodium (and aluminum) atoms per unit cell of in total 96 silicon and aluminum atoms. Alternatively: MOR-type sieves were made with 0.00, 0.10, and 0.17 sodium atoms per T-atom; MFI-type sieves were made with $0.00,0.02,0.03,0.05,0.06$, and 0.08 sodium atoms per $\mathrm{T}$ atom. The MOR models have been constructed from the crystallographic data of Meier. ${ }^{9}$ For MFI we have used the crystallographic structure of silicalite of van Koningsveld et al. ${ }^{11}$
TABLE 1: Lennard-Jones Parameters Used in Our Forcefield, $\epsilon / k_{\mathrm{B}}[\mathrm{K}]$ in the Upper Left Corner, $\sigma[\mathrm{A}]$ in the Lower Right Corner of Each Field ${ }^{a}$

\begin{tabular}{|c|c|c|c|c|c|c|c|c|c|}
\hline & $\mathbf{O}_{A 1}$ & $\mathbf{O}_{\mathrm{St}}$ & Al & $\mathbf{S i}$ & $\mathrm{Na}$ & $\mathrm{CH}$ & $\overline{\mathrm{CH}_{2}}$ & $\mathrm{CH}_{3}$ & $\mathrm{CH}_{4}$ \\
\hline $\mathrm{CH}_{4}$ & $\begin{array}{l}3.60 \\
96.5\end{array}$ & $\begin{array}{c}3.60 \\
96.5\end{array}$ & $\begin{array}{l}3.60 \\
96.5\end{array}$ & $\begin{array}{c}3.60 \\
96.5\end{array}$ & $\begin{array}{c}2.65 \\
508.0\end{array}$ & $\begin{array}{l}4.18 \\
38.5\end{array}$ & $\begin{array}{l}3.84 \\
82.5\end{array}$ & $\begin{array}{c}3.74 \\
120.4\end{array}$ & $\begin{array}{c}3.73 \\
148.0\end{array}$ \\
\hline $\mathrm{CH}_{3}$ & $\begin{array}{l}3.60 \\
80.0\end{array}$ & $\begin{array}{c}3.60 \\
80.0\end{array}$ & $\begin{array}{r}3.60 \\
80.0\end{array}$ & $\begin{array}{c}3.60 \\
80.0\end{array}$ & $\begin{array}{l}2.63 \\
435.0\end{array}$ & $\begin{array}{l}4.19 \\
31.3\end{array}$ & $\begin{array}{l}3.85 \\
\quad 67.1\end{array}$ & $\begin{array}{l}3.75 \\
98.0\end{array}$ & \\
\hline $\mathrm{CH}_{2}$ & $\begin{array}{l}3.60 \\
58.0\end{array}$ & $\begin{array}{c}3.60 \\
58.0\end{array}$ & 3.60 & $\begin{array}{l}3.60 \\
58.0\end{array}$ & $\begin{array}{l}2.61 \\
359.0\end{array}$ & 4.30 & $\begin{array}{l}3.95 \\
46.0\end{array}$ & & \\
\hline CH & $\begin{array}{l}3.60 \\
58.0\end{array}$ & $\begin{array}{c}3.60 \\
58.0\end{array}$ & $\begin{array}{l}3.60 \\
58.0\end{array}$ & ${ }^{3.60}{ }_{58.0}$ & $\begin{array}{l}2.58 \\
292.0\end{array}$ & $\begin{array}{l}4.68 \\
10.0\end{array}$ & & & $q[0]$ \\
\hline $\mathbf{N a}$ & \begin{tabular}{|c|}
2.33 \\
$\quad 304.6$ \\
\end{tabular} & \begin{tabular}{|c|}
2.33 \\
$\quad 304.6$ \\
\end{tabular} & \begin{tabular}{|l|}
2.33 \\
$\quad 304.6$ \\
\end{tabular} & \begin{tabular}{|l|}
2.33 \\
$\quad 304.6$ \\
\end{tabular} & \begin{tabular}{|l|l}
2.33 \\
304.6 \\
\end{tabular} & & & $\mathrm{Na}$ & +1.00 \\
\hline Si & -- & -- & -- & -- & & & & $\mathrm{O}_{\mathrm{si}}$ & .1025 \\
\hline Al & -- & -- & -- & & & & & $0_{11}$ & -1.20 \\
\hline $\mathrm{O}_{\mathrm{Si}}$ & -- & -- & & & & & & Si & +2.05 \\
\hline $\mathbf{O}_{\mathrm{Al}}$ & -- & & & & & & & AI & +1.75 \\
\hline
\end{tabular}

${ }^{a}$ The partial charges of the zeolite and the sodium ions are given at the lower right corner of the table. $\mathrm{O}_{\mathrm{Al}}$ are oxygens bridging one silicon and one aluminum atom, and $\mathrm{O}_{\mathrm{Si}}$ are oxygens bridging two silicon atoms. Due to the symmetry, only the upper part of the table is shown.

in which $\mathrm{Si}$ atoms were substituted by $\mathrm{Al}$ atoms at the preferred positions as indicated by Stave and Nicholas ${ }^{29}$ and AlvaradoSwaisgood et al. ${ }^{30}$ The structures corresponding to the highest framework aluminum density were taken directly from these works. Zeolite structures with lower framework aluminum density were obtained by randomly substituting $\mathrm{Al}$ by Si atoms. In all cases the simulation box is chosen large enough to obey the minimum image convention with a potential cutoff of 13.8 $\AA$. The simulation boxes of MFI are supercells that consist of 16 orthorhombic cells $(2 \times 2 \times 4, a=20.1 \AA, b=19.7 \AA$, and $c=13.1 \AA$ ) and the boxes of MOR contain 30 orthorhombic cells $(3 \times 2 \times 5, a=18.3 \AA, b=20.5 \AA$, and $c=7.5 \AA)$; periodic boundary conditions are applied in all directions.

2.2. Interatomic Potentials Details. We have performed calculations in which the interactions of atoms of adsorbed molecules (alkanes and sodium cations) with other adsorbates and the zeolite are modeled by Lennard-Jones and Coulombic interactions. The alkanes are described with a united atom model, in which each $\mathrm{CH}_{n}$ group is treated as a single interaction center. ${ }^{31}$ The interactions between these pseudo-atoms are given by Lennard-Jones potentials in which the parameters are chosen to reproduce the vapor-liquid curve of the phase diagram as shown by Siepmann et al. ${ }^{32}$ The interactions of the adsorbed molecules with the zeolite are dominated by the dispersive forces between the pseudo-atoms and the oxygen atoms of the zeolite $^{33,34}$ meaning that the silicon interactions are taken into account through an effective potential with only the oxygens. The nonframework sodium cations are also described as single interaction centers, but these are charged. Table 1 lists all the Lennard-Jones parameters used in this work. ${ }^{18,35}$

The zeolite lattices are rigid during the simulations but the nonframework sodium cations are allowed to move. Several authors have performed simulations using flexible zeolites ${ }^{14,36}$ showing that a flexible lattice can influence diffusion properties. To diffuse inside a zeolite the molecules have to go through narrow windows forming energy barriers. In a flexible zeolite, fluctuations in the size and shape of the window are able to change the height of these energy barriers. However, our study focuses at the low energy, equilibrium configurations, so that the fluctuations in the high energy configurations in flexible zeolite models are negligible. ${ }^{37}$

The Coulomb interactions in the system are calculated using the Ewald summation for periodic systems. ${ }^{38}$ We have defined our systems with static charges, which implies that we ignore the polarization of oxygen by nearby sodium cations. In previous 
studies, charges involved in calculations with zeolites and cations have been handled in two different ways. In some works there was no distinction between $\mathrm{Si}$ and $\mathrm{Al}$ charges, ${ }^{39-46}$ whereas other works explicitly include $\mathrm{Al}$ in the model and center the charge difference around the $\mathrm{Al}$ atoms. ${ }^{18,47,48}$ Our aim is to study the influence of aluminum position in the adsorption properties of zeolites and therefore, our model explicitly distinguishes silicon from aluminum. Atomic charges are assigned by choosing $q_{\mathrm{Na}}=1$ and a difference of 0.3 between $q_{\mathrm{Si}}$ and $q_{\mathrm{Al}}{ }^{49}$ Different charges are used for oxygen atoms bridging two silicon atoms, $q_{\mathrm{OSi}}$, and oxygens bridging one silicon and one aluminum atom $q_{\mathrm{OAl}} \cdot q_{\mathrm{OSi}}$ is obtained using the relation $q_{\mathrm{Si}}+\left(2 \times q_{\mathrm{OSi}}\right)$ $=0$, making the zeolite neutral in the absence of aluminum, while $q_{\mathrm{OAl}}$ is chosen so as to make the total system charge equal to zero. ${ }^{48}$ All partial charges are listed in Table 1.

2.3. Simulation Technique. Adsorption isotherms were computed using CBMC simulation in the grand-canonical ensemble. In this ensemble the volume, temperature, and chemical potential are fixed and the number of particles is able to fluctuate during the simulation. In a grand canonical simulation particles are exchanged with a reservoir, which is at the same chemical potential. The equilibrium conditions are equal temperature and equal chemical potential of the gas inside and outside the zeolite. The fugacity of a gas $(f)$ is its effective thermodynamic pressure and is defined so that the chemical potential of the gas is given by the expression

$$
\mu=\mu^{\circ}+R T \ln \left(\frac{f}{p^{\circ}}\right)
$$

where $p^{\circ}$ and $\mu^{\circ}$ are the standard pressure and chemical potential, respectively. Fugacities and pressures are related through the expression: $f=\phi p$, where $\phi$ is the fugacity coefficient. In the conditions considered in this work it is acceptable to simply replace the fugacities by pressures. However, when the pressure in the reservoir is too high for the ideal gas law to hold, we have to use the fugacity coefficient, which can be obtained through an (experimental or simulated) equation of state.

The adsorption isotherms are obtained as a function of the pressure and they are given in millimoles of alkane per gram of zeolite. The atoms forming the framework (silicon, aluminum, and oxygen) determine the density of the zeolite. The simulations yield absolute adsorptions, which can be compared with experimental isotherms when they are corrected for surface excess adsorption..$^{50,51}$

In CBMC simulations, molecules are grown segment by segment, ${ }^{38}$ avoiding overlap. For each segment, a set of trial orientations is generated. One of the trial positions is selected according to the Boltzmann weight of the zeolite energy, and this selected trial orientation is added to the chain. The procedure is repeated until the entire molecule has been grown. The rules for acceptance or rejection of a grown molecule are chosen in a way that they exactly remove the bias caused by this growing scheme.

Simulations are performed in cycles and in each cycle one move is chosen at random with a fixed probability of performing a molecule displacement (0.15), rotation around the center of mass (0.15), exchange with the reservoir (0.55), and partial regrowth of a molecule $(0.15)$. For mixtures we include an exchange of the type of molecules (0.05) and an exchange with the reservoir $(0.5)$. The maximum translational and rotational displacements are adjusted to achieve an acceptance probability of $50 \%$. The total number of cations remains constant during simulations so only translation movements are considered for this type of particles.

Henry coefficients were computed in the NVT ensemble including translation $(0.1)$, rotation $(0.1)$, partial regrowths $(0.1)$ and regrowths of the entire molecule (0.7). For the NVT simulations the total number of cycles was at least $1 \times 10^{7}$. For the grand-canonical simulations the number of cycles for one-component isotherms was $2 \times 10^{7}$ and at least $3 \times 10^{7}$ for the mixtures.

\section{Results and Discussion}

In the present work we have studied in detail the effect of framework and nonframework cations on adsorption behavior and selectivity in MFI and MOR structures. Below we present our results divided into three sections: (i) nonframework cations location and Al distribution, (ii) nonframework sodium density, and (iii) adsorption selectivity.

3.1. Nonframework Cations Location and Al Distribution. The positions and stability of sodium cations in the zeolite are strongly related to its $\mathrm{Al}$ distribution. ${ }^{52}$ We have used Monte Carlo simulations to predict the location of nonframework sodium cations in MFI and MOR structures with several framework aluminum densities. During the simulations, interactions of sodium cations with framework atoms, other sodium cations, and alkane molecules have been considered. This allows the particles to move freely in the system. However, due to the strong Coulombic interactions with the zeolite framework, we found that the cations are distributed in a narrow region around the oxygen atoms' neighboring aluminum atoms. Molecular pictures and distribution function data, taken from our simulations (not shown here), revealed a location of sodium cations in agreement with the available experimental data ${ }^{13}$ for MOR with 8 aluminum atoms per unit cell.

The distribution of aluminum over the framework sites in zeolites is known to influence their catalytic properties. At the aluminum concentration typical for MFI and MOR it has proved as yet impossible to measure the distribution of aluminum over the different $\mathrm{T}$-sites in these structures (12 nonequivalent crystallographic T-sites in MFI and 4 distinct sites in MOR). As mentioned before, in MFI-type zeolites we have used the crystallographic structure of silicalite of van Koningsveld et al. ${ }^{11}$ In this structure $\mathrm{T} 12$ is the preferred site for $\mathrm{Al}$ substitution according to Stave and Nicholas ${ }^{29}$ and Alvarado-Swaisgood et al. $^{30}$

In MOR-type zeolites, the structure corresponding to the highest framework aluminum density ( 8 aluminum atoms per unit cell) was taken directly from crystallographic data; ${ }^{9}$ zeolite structures with lower framework aluminum densities were obtained by randomly removing $\mathrm{Al}$ atoms and replacing them with $\mathrm{Si}$ atoms following the criteria of some previous works. ${ }^{53-56}$ To analyze the influence of this random Al-substitution in the adsorption properties, we have computed the adsorption isotherms of ethane at $296 \mathrm{~K}$ in MOR with a framework aluminum density of 5 atoms per unit cell. Our simulations, in Figure 1, show that at pressures higher than $100 \mathrm{kPa}$ the eight models lead to very similar results. At these high loadings the number of molecules adsorbed does not seem to depend strongly on the position of the cations. On the contrary, in the lower pressure range spanning from 1 to $100 \mathrm{kPa}$, a different behavior is shown. To explain this behavior we have to consider the structure of MOR and the fact that at low pressures ethane molecules adsorb preferentially in the side pockets as we show in detail in Section 3.2. Thus, structures with a large amount of aluminum near the 
TABLE 2: Henry Coefficients [mg/g/kPa] for Methane, Ethane, and Propane in MFI- and MOR-Type Zeolites with Different Nonframework Sodium Densities Given in Sodium Cations per Unit Cell $\left(\mathrm{Na}^{+} / \mathrm{uc}\right)^{a}$

\begin{tabular}{|c|c|c|c|c|c|c|c|c|c|c|c|}
\hline \multirow{2}{*}{\multicolumn{2}{|c|}{$\mathrm{Na}^{+} / \mathrm{uc}$}} & \multirow[b]{2}{*}{$T[\mathrm{~K}] \rightarrow$ source } & \multicolumn{3}{|c|}{ methane } & \multicolumn{3}{|c|}{ ethane } & \multicolumn{3}{|c|}{ propane } \\
\hline & & & 273.15 & 296.15 & 323.15 & 273.15 & 296.15 & 323.15 & 273.15 & 296.15 & 323.15 \\
\hline \multirow[t]{3}{*}{ MFI } & 0 & this work & 0.261 & 0.132 & 0.067 & 13.178 & 4.643 & 1.660 & 258.06 & 67.473 & 17.867 \\
\hline & 5 & this work & 0.205 & 0.102 & 0.051 & 8.996 & 3.049 & 1.050 & 164.89 & 40.845 & 10.455 \\
\hline & 8 & this work & 0.167 & 0.087 & 0.046 & 7.047 & 2.599 & 0.966 & 76.093 & 18.836 & 4.787 \\
\hline \multirow[t]{7}{*}{ MOR } & 0 & this work & 0.141 & 0.073 & 0.038 & 3.712 & 1.575 & 0.670 & 85.304 & 27.497 & 8.8704 \\
\hline & & Mac. sim. & 0.245 & 0.115 & 0.056 & 9.039 & 2.881 & 0.974 & & & \\
\hline & 5 & this work & 0.508 & 0.231 & 0.107 & 35.752 & 11.831 & 3.974 & 3286.5 & 741.41 & 156.14 \\
\hline & & Mac. sim. & 0.475 & 0.208 & 0.092 & 32.911 & 9.053 & 2.494 & & & \\
\hline & 8 & this work & 0.959 & 0.410 & 0.180 & 90.667 & 28.965 & 9.023 & 6458.5 & 1466.6 & 329.09 \\
\hline & & Mac. exp. & 0.925 & 0.401 & 0.175 & 79.103 & 23.984 & 7.783 & & & \\
\hline & & Mac. sim. & 0.815 & 0.333 & 0.143 & 61.744 & 15.905 & 4.157 & & & \\
\hline
\end{tabular}

${ }^{a}$ Comparison with experimental and simulation results on methane and ethane in MOR by Macedonia et al. ${ }^{18}$

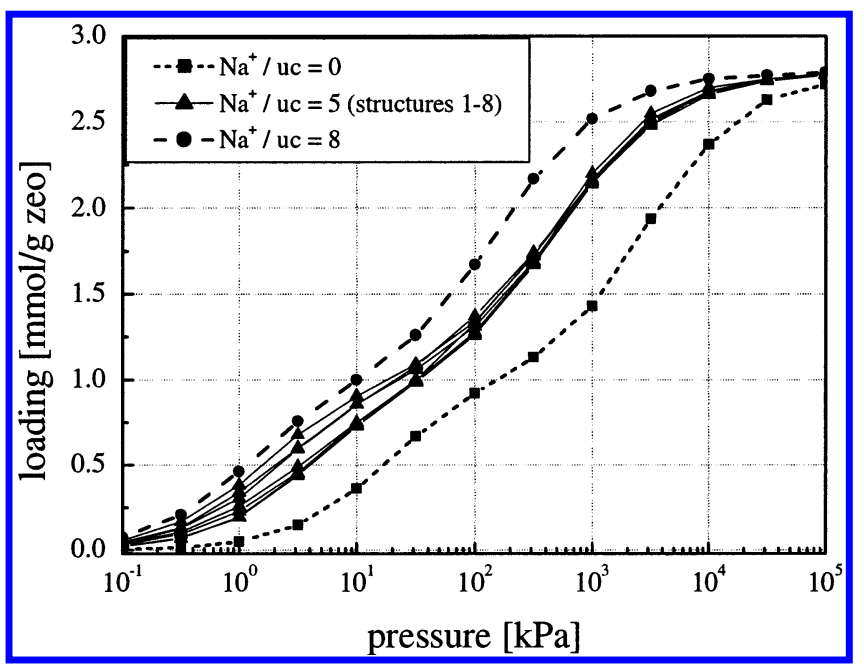

Figure 1. Simulated adsorption isotherms of ethane in MOR-type structures with 0,5 , and 8 sodium (aluminum) atoms per unit cell $\left(\mathrm{Na}^{+} /\right.$ uc) at $296 \mathrm{~K}$. Eight different structures of MOR with 5 sodium cations per unit cell are plotted. The structure corresponding to 8 sodium cations per unit cell (full circles) was taken directly from crystallographic data while the eight structures corresponding to 5 sodium cations per unit cell (full triangles) were constructed by randomly removing $\mathrm{Al}$ atoms from this structure and replacing them by silicon atoms.

side pockets present a lower adsorption capacity at low pressures, since the sodium cations (always near the oxygens bridging one silicon and one aluminum atom) are blocking the access to the side pockets.

3.2. Nonframework Sodium Density. To study the effect of the sodium density on adsorption behavior, we performed simulations to obtain adsorption isotherms and Henry coefficients of methane, ethane, and propane in MOR and MFI structures at several temperatures $(273,296$, and $323 \mathrm{~K})$. In these simulations we vary the sodium density over a wide range of pressures. The computed Henry coefficients are listed in Table 2. As expected, Henry coefficients decrease with increasing temperature. In addition we found a decrease with decreasing sodium density in MOR or with increasing sodium density in MFI. In Table 2 we also report some data from previous work ${ }^{18}$ (simulations and experiments) in MOR-type structures showing a good agreement.

The effect of decreasing the sodium density in MOR is plotted in Figure 2. Figure 2a shows the single component adsorption isotherms for methane at $273 \mathrm{~K}$ for 0,5 , and 8 sodium cations per unit cell, respectively. The isotherms corresponding to the $5 \mathrm{Na}^{+} /$uc structures were obtained by averaging over the eight structures considered previously in Figure 1. At a given pressure, a decrease in the amount of adsorption is observed when the sodium density is decreased. In Figure $2 b$ the effect of decreasing the sodium density on the adsorption of ethane at $296 \mathrm{~K}$ is shown. As with methane, we have detected a decrease in adsorption at a given pressure with decreasing sodium density. A similar trend is observed for propane (Figure 2c). The nonideal adsorption behavior of ethane at low pressures in our simulations (an inflection point is observed) is a consequence of the fact that the side pockets are the preferred adsorption sites in these structures at room temperature. After these sites fill, the main channels become occupied. These results are consistent with previous work. ${ }^{16-18,57}$

Figure 3 shows the effect of decreasing the sodium density on the adsorption of methane (Figure 3a), ethane (Figure 3b), and propane (Figure 3c) in MFI. Contrary to MOR, the expected increase in the amount of adsorption is observed with removal of more cations from the channels. The explanation is related to the structural differences between MFI and MOR. To illustrate this, Figure 4 schematically depicts the adsorption of propane in both zeolites. MOR consists of channels $(6.8 \AA)$ that are wide enough to accommodate sodium cations and alkane molecules next to each other. The sodium ions have favorable van der Waals interactions with the alkane molecules; i.e., they act as an "extra wall". These interactions favor the adsorption of more molecules, and therefore the loading increases with an increasing amount of sodium ions (and aluminum atoms) present in the zeolite. On the other hand, MFI consists of straight channels that are intersected by zigzag channels. These channels are narrower than in MOR (5.4 $\AA$ ) and therefore sodium ions and alkane molecules do not fit next to each other in a pore, thus eliminating the favorable van der Waals interaction. Furthermore, as the aluminum atoms are located at the intersections of the zigzag channels with the straight channels, the preferred positions of the charge-compensating sodium ions are also at these intersections. Therefore, the positions at the intersections of the zeolite are blocked by the sodium ions and become inaccessible for the alkane molecules, limiting the number of alkane molecules that fit inside the zeolite and causing a decrease in the adsorption. The simulated adsorption isotherms of propane are compared in Table 3 with experimental data, ${ }^{19}$ showing a reasonable agreement.

In previous simulations, $\mathrm{Du}$ et al. found at room temperature a small inflection point in the adsorption isotherm of ethane at high loadings in MFI-type silica. ${ }^{58}$ This inflection point was attributed to special ordering effects of the alkane in the silica. Referring again to Figure 3, it is of interest to note that our simulations for all-silica sieves also show an additional rise in the adsorption isotherm of methane and ethane (Figure 3a,b) near the maximum loading. Since this rise disappears with the 

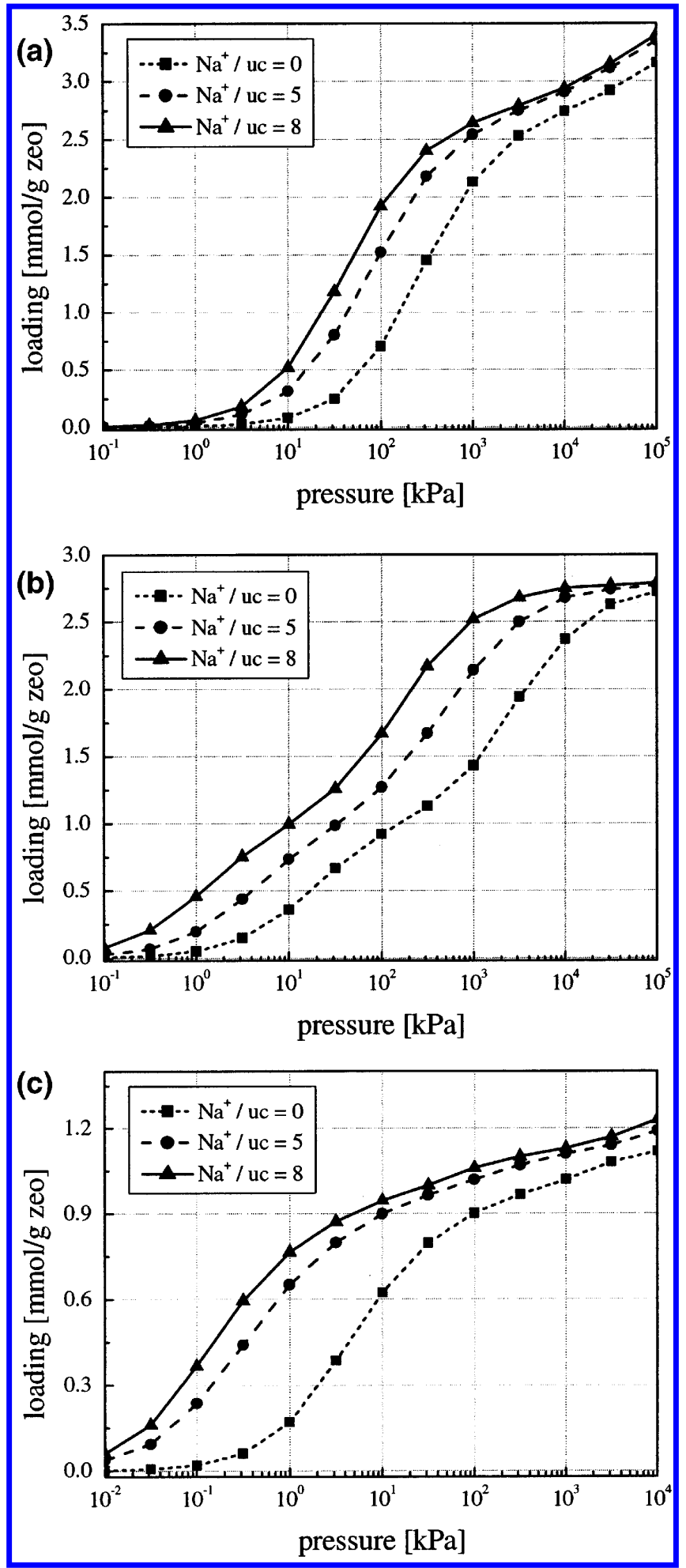

Figure 2. Simulated adsorption isotherms in MOR-type structures with 0,5 , and 8 sodium cations per unit cell $\left(\mathrm{Na}^{+} / \mathrm{uc}\right)$; (a) methane at 273 $\mathrm{K}$, (b) ethane at $296 \mathrm{~K}$, (c) propane at $323 \mathrm{~K}$.

introduction of nonframework sodium into the zeolite channels, we provide here a more specific explanation for this effect. To illustrate our explanation, the amount of molecules of ethane adsorbed per unit cell in the intersections and internal channels of MFI-type sieves with and without nonframework sodium as a function of pressure are shown in Figure 5, parts a and b, respectively. This figure shows that the number of molecules of ethane adsorbed in the channels does not depend on the presence of nonframework sodium in the channels and it is
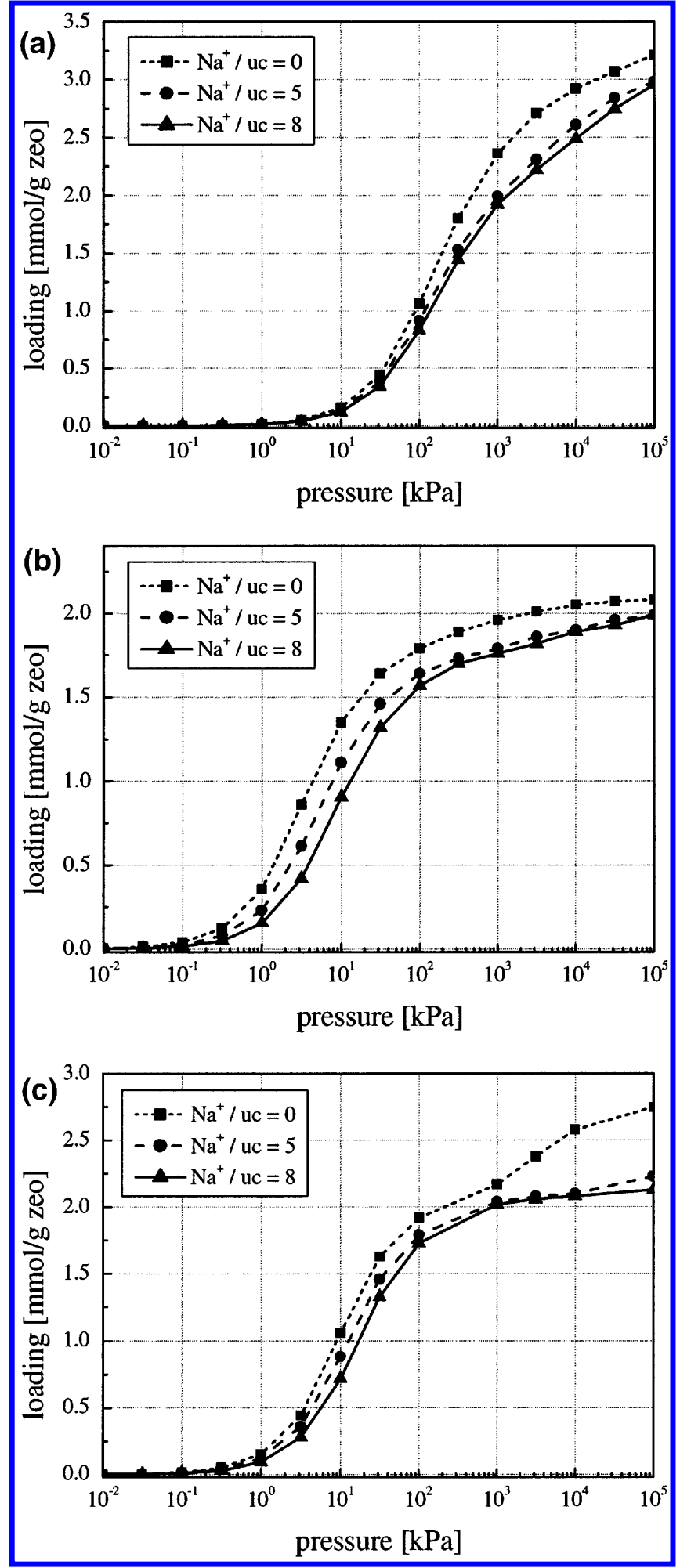

Figure 3. Simulated adsorption isotherms in MFI-type structures with 0,5 , and 8 sodium cations per unit cell $\left(\mathrm{Na}^{+} / \mathrm{uc}\right)$; (a) methane at 273 $\mathrm{K}$, (b) ethane at $296 \mathrm{~K}$, (c) propane at $323 \mathrm{~K}$.

almost constant above $100 \mathrm{kPa}$. However, a clearly different behavior is observed in the intersections. Figure 5a shows that at $1000 \mathrm{kPa}$ there is an increase in the number of particles adsorbed in the intersections of MFI-type sieves without nonframework sodium, while this amount remains constant when sodium cations are introduced (Figure 5b). From our simulations we are able to conclude that at high pressures, when the zeolite is almost full, it is possible to "push" some extra 


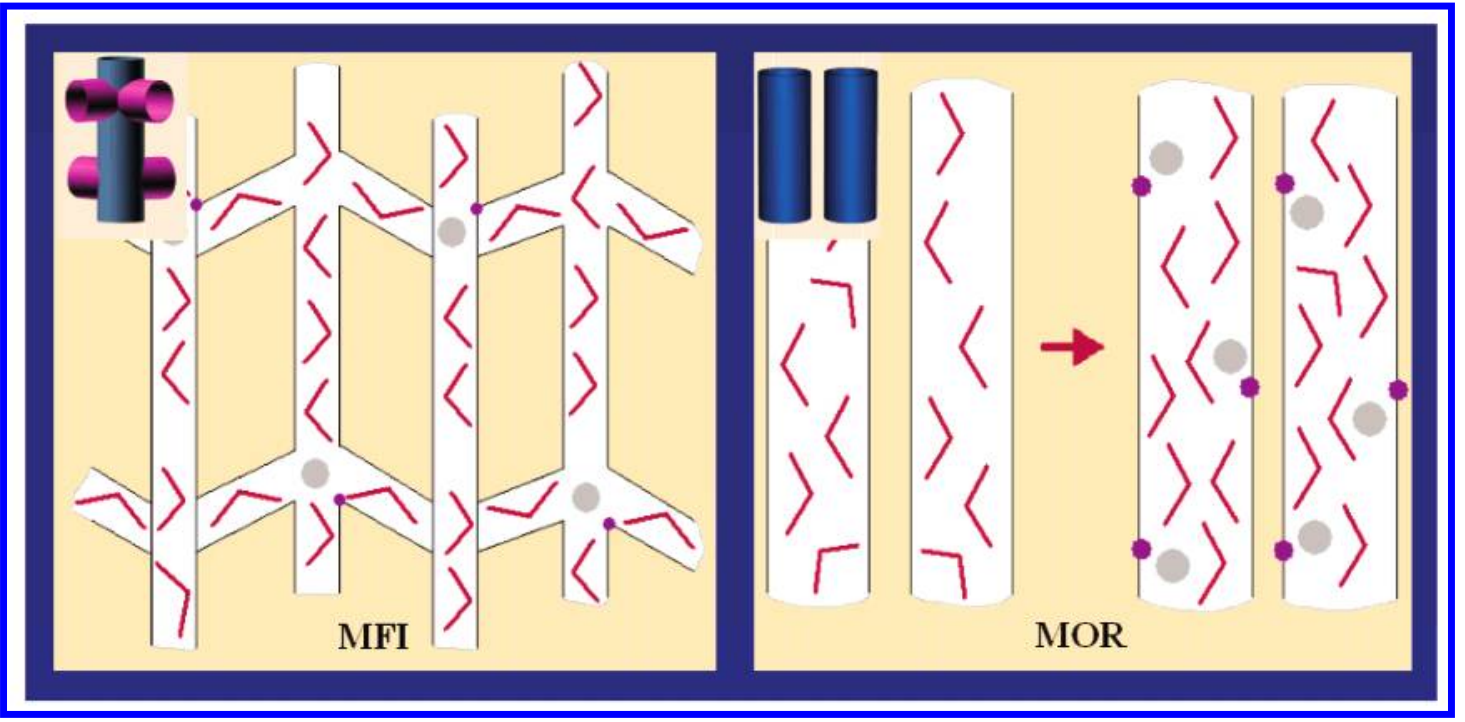

Figure 4. Schematic representation of the adsorption of propane in MFI and MOR. Small, dark spots: aluminum atoms; larger, lighter circles: sodium cations; bent lines: propane molecules.

TABLE 3: Adsorption [mmol/g zeolite] of Propane in MFI-Type Zeolites with 3 and 6 sodium cations per unit cell $\left(\mathrm{Na}^{+} / \mathrm{uc}\right)$, at Several Pressures and Temperatures ${ }^{a}$

\begin{tabular}{|c|c|c|c|c|c|c|}
\hline \multirow[b]{3}{*}{$\begin{array}{c}T \\
{[\mathrm{~K}]}\end{array}$} & \multirow[b]{3}{*}{$\begin{array}{c}p \\
{[\mathrm{kPa}]}\end{array}$} & \multicolumn{2}{|c|}{$\mathrm{Na}^{+} / \mathrm{uc}=3$} & \multicolumn{3}{|c|}{$\mathrm{Na}^{+} / \mathrm{uc}=6$} \\
\hline & & \multicolumn{2}{|c|}{$\begin{array}{c}\text { adsorption } \\
{[\mathrm{mmol} / \mathrm{g} \text { zeo] }}\end{array}$} & \multirow[b]{2}{*}{$\begin{array}{c}p \\
{[\mathrm{kPa}]}\end{array}$} & \multicolumn{2}{|c|}{$\begin{array}{c}\text { adsorption } \\
{[\mathrm{mmol} / \mathrm{g} \text { zeo }]}\end{array}$} \\
\hline & & $\begin{array}{l}\text { this } \\
\text { work }\end{array}$ & $\begin{array}{l}\text { Calleja et al. } \\
\text { (exp.) }\end{array}$ & & $\begin{array}{l}\text { this } \\
\text { work }\end{array}$ & $\begin{array}{l}\text { Calleja et al. } \\
\quad \text { (exp.) }\end{array}$ \\
\hline \multirow[t]{6}{*}{281} & 1.12 & 1.285 & 1.365 & 2.60 & 1.389 & 1.497 \\
\hline & 5.67 & 1.640 & 1.554 & 7.66 & 1.553 & 1.568 \\
\hline & 11.97 & 1.725 & 1.598 & 17.44 & 1.644 & 1.611 \\
\hline & 28.37 & 1.797 & 1.651 & 34.23 & 1.676 & 1.650 \\
\hline & 52.67 & 1.844 & 1.691 & 55.12 & 1.723 & 1.666 \\
\hline & 80.78 & 1.870 & 1.710 & 83.20 & 1.734 & 1.687 \\
\hline \multirow[t]{7}{*}{293} & 7.63 & 1.565 & 1.476 & 3.71 & 1.289 & 1.298 \\
\hline & 16.16 & 1.671 & 1.538 & 8.06 & 1.429 & 1.490 \\
\hline & 29.18 & 1.742 & 1.577 & 18.96 & 1.595 & 1.556 \\
\hline & 53.44 & 1.792 & 1.607 & 33.77 & 1.625 & 1.587 \\
\hline & 74.40 & 1.815 & 1.631 & 54.70 & 1.676 & 1.611 \\
\hline & 91.20 & 1.827 & 1.665 & 71.51 & 1.691 & 1.626 \\
\hline & & & & 88.06 & 1.720 & 1.651 \\
\hline \multirow[t]{7}{*}{309} & 2.05 & 0.792 & 1.069 & 3.71 & 0.911 & 1.229 \\
\hline & 6.04 & 1.268 & 1.247 & 10.63 & 1.305 & 1.334 \\
\hline & 13.50 & 1.493 & 1.337 & 19.21 & 1.432 & 1.396 \\
\hline & 22.77 & 1.590 & 1.380 & 42.51 & 1.570 & 1.456 \\
\hline & 44.36 & 1.683 & 1.478 & 64.10 & 1.590 & 1.539 \\
\hline & 64.01 & 1.720 & 1.536 & 90.37 & 1.641 & 1.605 \\
\hline & 87.24 & 1.748 & 1.594 & & & \\
\hline
\end{tabular}

${ }^{a}$ Comparison with experimental data by Calleja et al. ${ }^{19}$

molecules into the intersections. This is not possible in the presence of sodium cations because the cations are already occupying the very same intersections. The amount of molecules of propane adsorbed in MFI-type sieves is shown in Figure 6, parts a and $b$, respectively. Here no additional rise has been found, even though the presence of sodium decreases the number of molecules of propane adsorbed in the intersections.

3.3. Adsorption Selectivity. Separation in zeolites is based on differences in diffusion rates, adsorption, and molecular size. To test the influence of the zeolite type and sodium cation density in isomers separations we have carried out simulations of adsorption of a 50/50 equimolar mixture of $n$-butane and isobutane in MFI- and MOR-type sieves. Simulations were performed at $100 \mathrm{kPa}$ over a temperature range of $300-525 \mathrm{~K}$. For each binary system three nonframework sodium densities
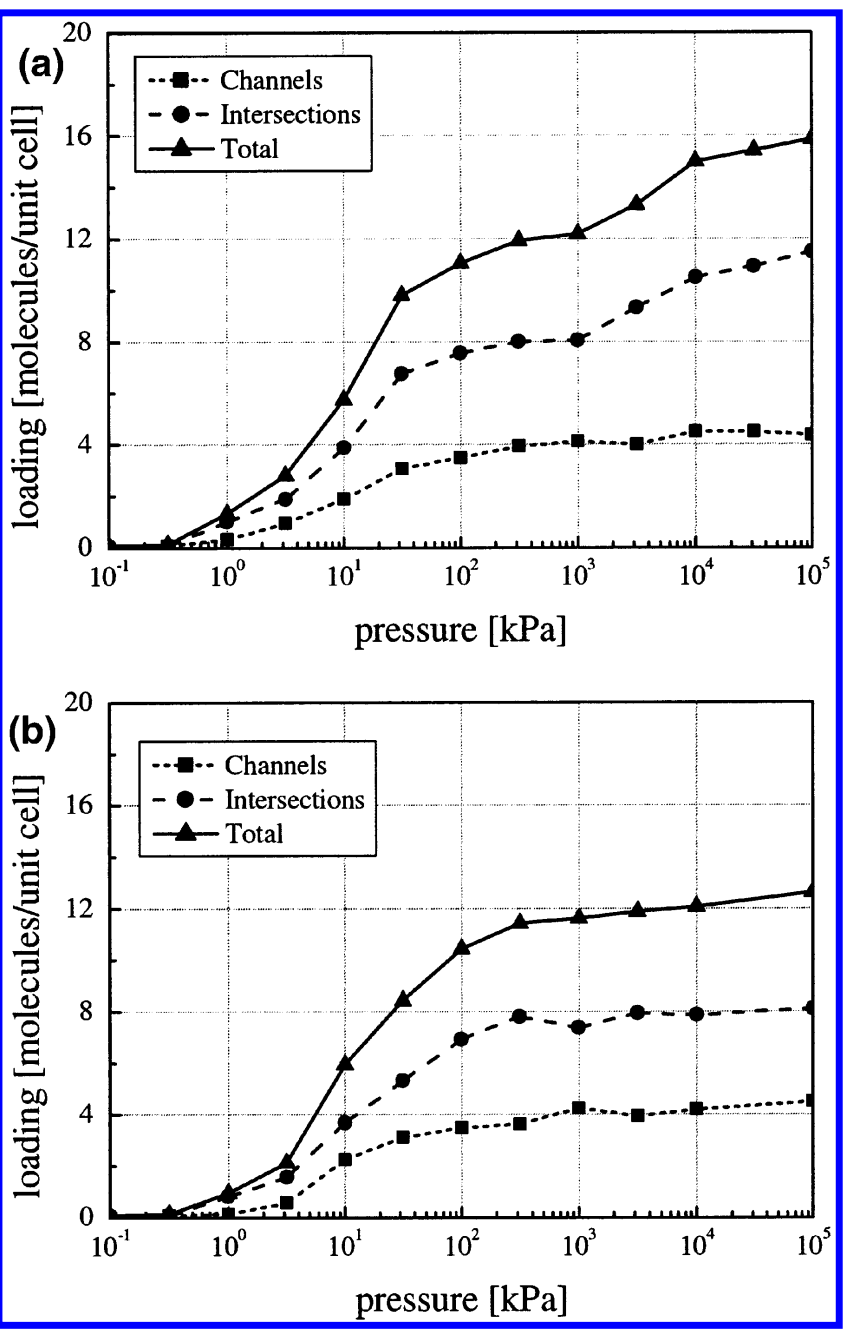

Figure 5. Number of molecules of ethane adsorbed in the intersections and in the channels as a function of pressure at $296 \mathrm{~K}$; (a) MFI without nonframework sodium, (b) MFI with 5 sodium cations per unit cell $\left(\mathrm{Na}^{+} / \mathrm{uc}\right)$. The loading of the intersections is defined as the number of molecules adsorbed within an arbitrary $5.5 \AA$ distance from the middle point of an intersection.

( $\mathrm{Si} / \mathrm{Al}$ ratios) have been considered. Figure $7 \mathrm{a}$ shows the $n$-butane/isobutane adsorption selectivity (defined by $S=\left(\Theta_{1} /\right.$ $\left.\Theta_{2}\right) /\left(p_{1} / p_{2}\right)$ where $\Theta_{i}$ and $p_{i}$ represent the component loading 

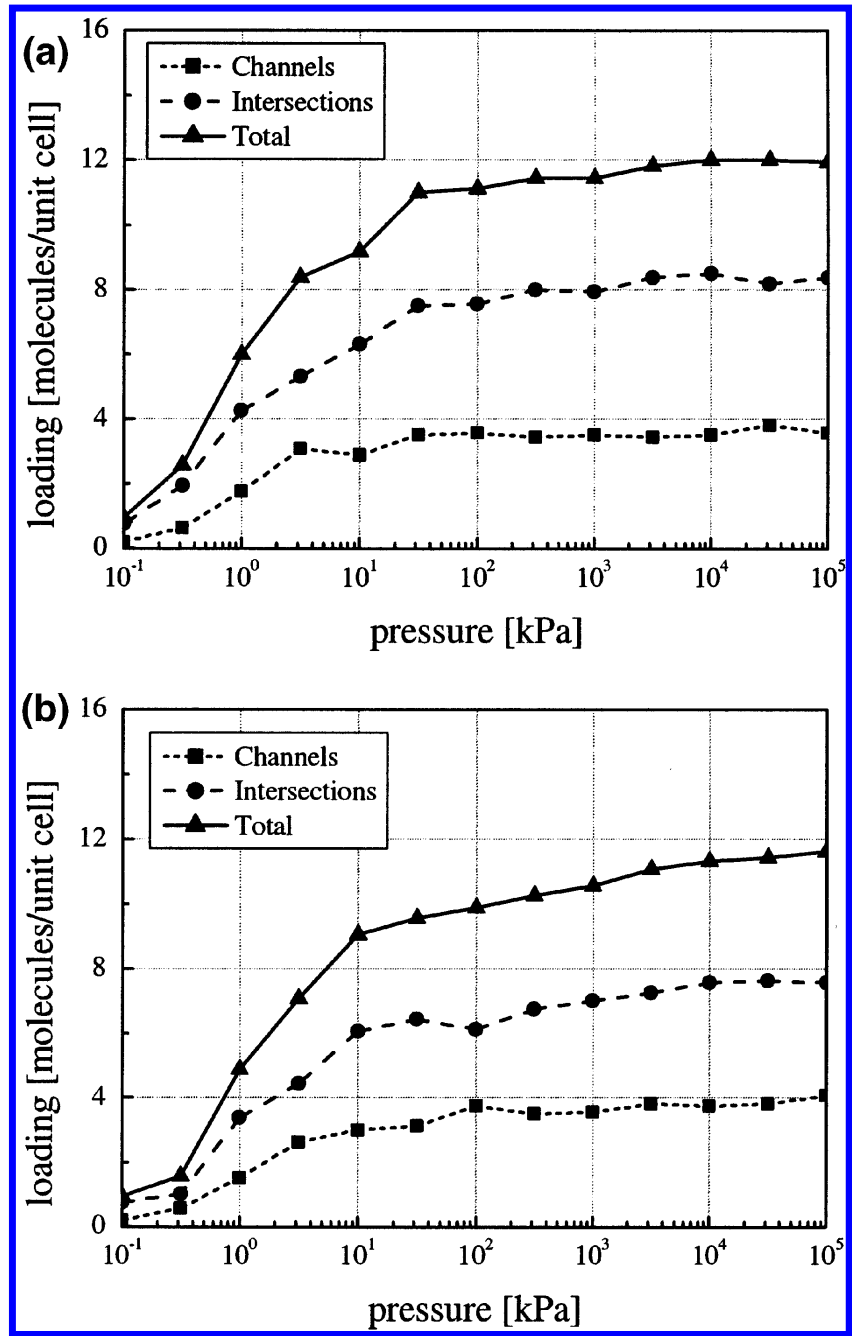

Figure 6. Number of molecules of propane adsorbed in the intersections and in the channels as a function of pressure at $296 \mathrm{~K}$; (a) MFI without nonframework sodium, (b) MFI with 5 sodium cations per unit cell $\left(\mathrm{Na}^{+} / \mathrm{uc}\right)$. The loading of the intersections is defined as the number of molecules adsorbed within an arbitrary $5.5 \AA$ distance from the middle point of an intersection.

and partial pressure in the gas phase, respectively) as a function of temperature for MFI structures with 0,2 , and 5 sodium cations per unit cell. In addition, the adsorption selectivities for isobutane with respect to $n$-butane for MOR with 0,5 , and 8 sodium cations per unit cell are shown in Figure 7b. As could be expected, these selectivities decrease with increasing temperature. Note that independently of the sodium density, the adsorption selectivity is in favor of $n$-butane in MFI, while it favors isobutane in MOR structures. This is due to entropy effects. In MFI-type zeolites, for a mixture of linear and branched alkanes with the same number of carbon atoms, configurational entropy effects favor the linear isomer because such molecules pack more efficiently within the intersecting channel topology. Length entropy effects come into play for sorption of linear and branched alkanes within the cylindrical channels of MOR-type zeolites. Here, the branched alkane has the shortest length and can be packed better within the channels. ${ }^{8,25}$

Figure 7a shows similar temperature dependencies for $n$ butane/isobutane adsorption selectivities in MFI-type zeolites with a maximum as a function of temperature $(325-375 \mathrm{~K})$. Moreover, increasing the sodium density increases the $n$-butane/ isobutane separation selectivities. An explanation of this be-

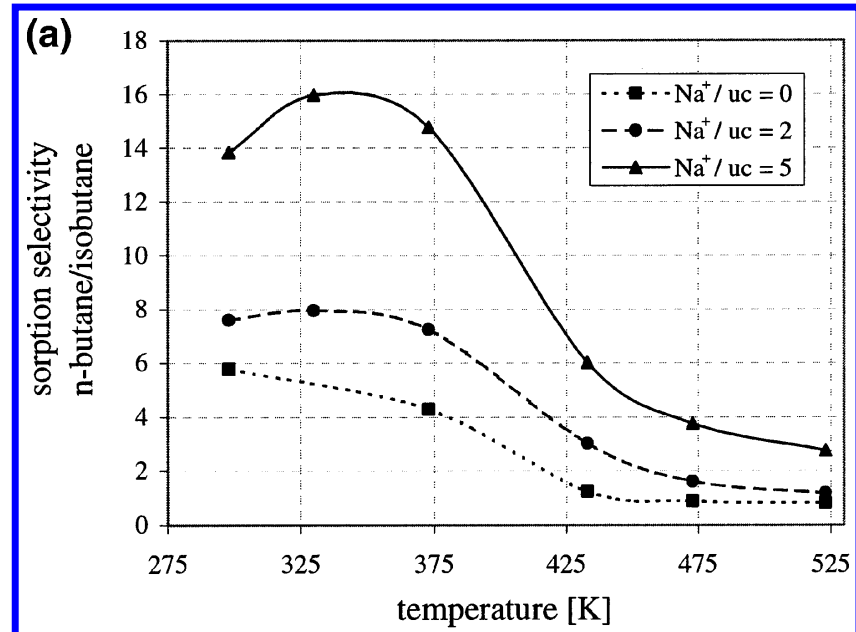

(b)

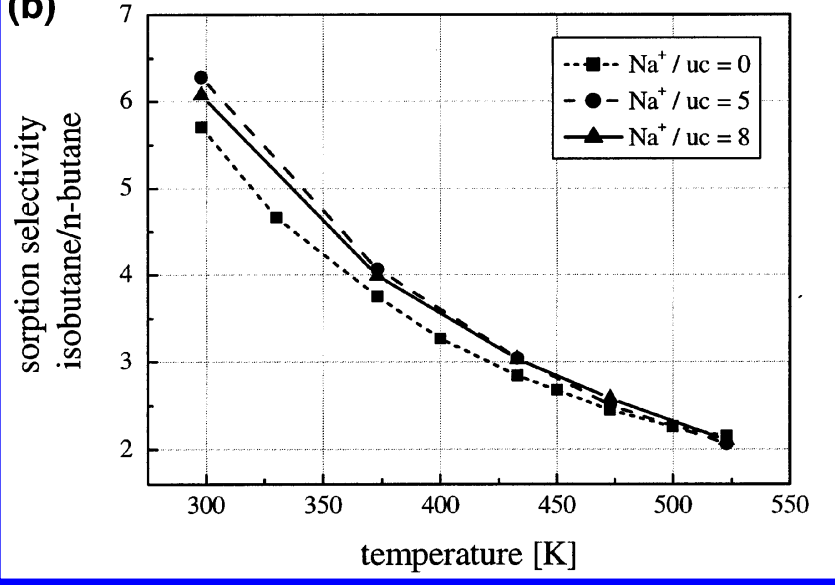

Figure 7. Adsorption selectivity as a function of temperature obtained from CBMC simulations at different nonframework sodium densities and at $100 \mathrm{kPa}$ : (a) $n$-butane/isobutane in MFI-type zeolites, (b) isobutane $/ n$-butane in MOR-type zeolites.

havior can be obtained from Figure 8a, where a schematic representation of the mixture adsorption in MFI is presented. The branched isomers prefer to locate at the intersections due to the fact that they fit better in them. Since the sodium cations in this structure are preferentially located at the intersections, the isobutane molecules are selectively blocked out of the zeolite and adsorption selectivity increases in favor of $n$-butane. Note that for the aluminum-containing structures the sorption selectivity decreases both at the lowest and the highest temperatures. As observed for pure-silica structures, the decrease at the highest temperatures is due to the lower total loading at these conditions. The selectivity decrease at the lowest temperature is observed only in the aluminum-containing structures. This behavior is caused by a size entropy effect. At these conditions, and when the zeolite almost reached its saturation loading, only the smallest alkanes (i.e., isobutane) can enter the zeolite, slowly decreasing the $n$-butane/isobutane sorption selectivity.

Finally, a schematic representation of a $n$-butane/isobutane mixture in MOR is shown in Figure $8 b$. As explained before, in this type of zeolite, isobutane molecules are preferred over $n$-butane. The amount of cations does not affect the isobutane/ $n$-butane selectivity since the channels are wide enough for sodium to fit in next to either an isobutane or an $n$-butane molecule.

Previous experimental works measured the permeation selectivities for a 50/50 mixture of butane and isobutane at various temperatures across MFI-containing membranes. ${ }^{23,26-28}$ In these 


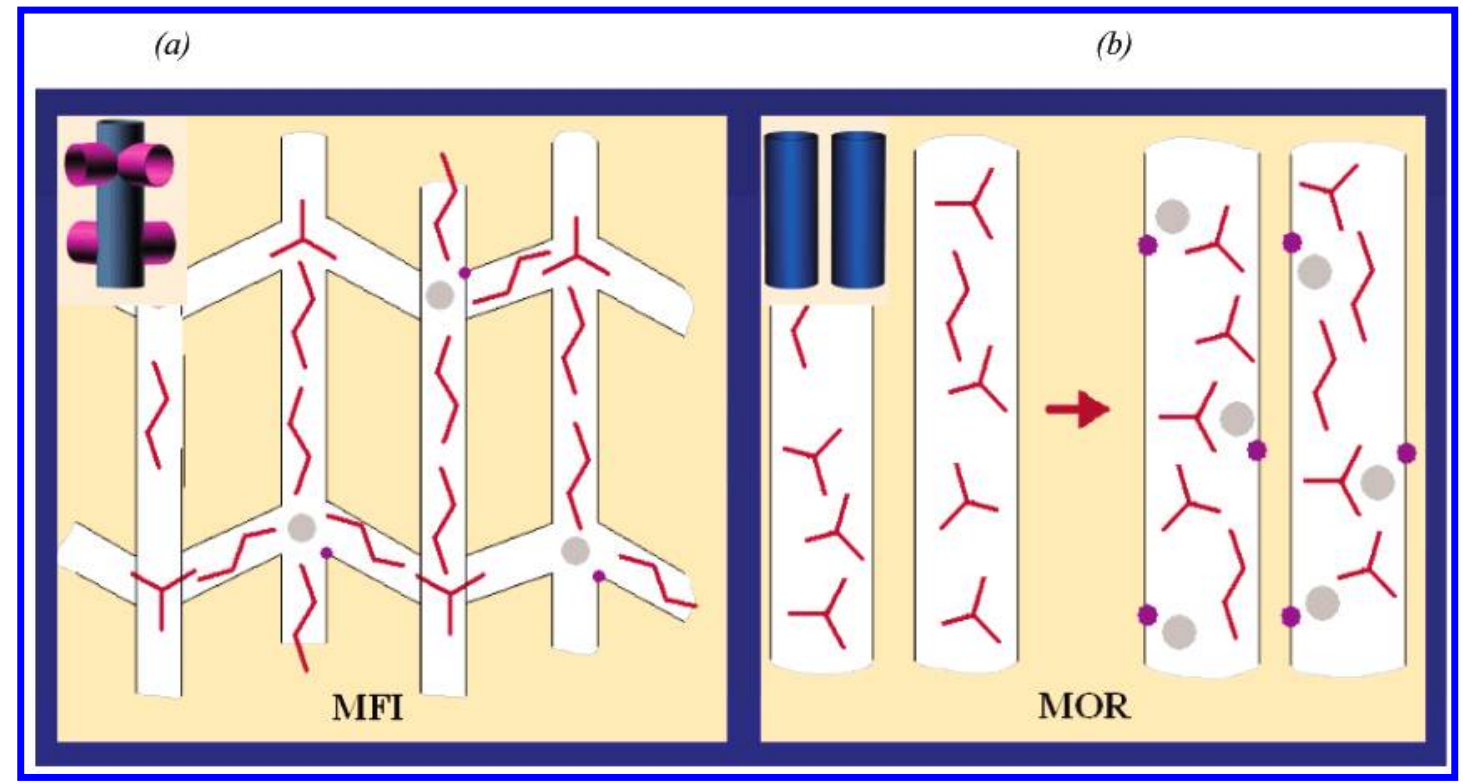

Figure 8. Schematic representation of a 50/50 mixture of butane and isobutane: (a) MFI, (b) MOR. Small, dark spots: aluminum atoms; larger, lighter circles: sodium ions.

works the $n$-butane/isobutane separation selectivities, $S_{\mathrm{p}}$, is the ratio between the permeation fluxes of the individual components in the mixture. Since the permeation flux of each component is assumed to be proportional to the diffusivity of that component and its molecular loading, ${ }^{6}$ the qualitative trends revealed by our adsorption selectivity simulations appear to agree well with experimental permeation selectivities. However, since the diffusivity of the branched alkane is known to be lower than the one for the linear alkane (meaning that the ratio of diffusivities of the linear and branched isomers is higher than unity), the experimental values for permeation selectivity are consistently higher than those obtained from our simulations.

\section{Conclusions}

In this work we have demonstrated that CBMC simulations are able to determine the adsorption properties of small alkanes $\left(\mathrm{C}_{1}-\mathrm{C}_{3}\right)$ in zeolites containing nonframework sodium cations and framework aluminum. First, we have analyzed the influence of crystal structure, cation locations, and cation loading on adsorption properties in MFI- and MOR-type zeolites, and second, we have studied the effect of sodium on the selective adsorption of binary mixtures of $\mathrm{C}_{4}$-isomers in these structures. An increase in the nonframework sodium density increases the $\mathrm{C}_{1}-\mathrm{C}_{4}$ loading in MOR-type zeolites, but slightly decreases the loading in MFI-type zeolites. Furthermore, increasing the sodium density does not affect the selectivity of MOR-type zeolites for adsorbing $n$-butane from $n$-butane/isobutane mixtures, but it markedly increases the selectivity of MFI-type zeolites.

Our simulations provided some molecular understanding of adsorption properties of small alkanes in these structures depending on the position of (non)framework cations. The MOR-type channels are large enough for nonframework sodium cations to provide favorable adsorption sites for the adsorbing alkanes, and thereby increase the alkane loading and selectivity for linear alkanes. The MFI-type channels are too small to accommodate both a sodium cation and an alkane, and, therefore, nonframework sodium cations only block adsorption sites, preferably at the intersections. In the absence of accessible intersections, the selectivity of MFI-type zeolites for adsorbing linear alkanes increases, but its adsorption capacity decreases.
Acknowledgment. These investigations are supported in part by The Netherlands Research Council for Chemical Sciences (CW) through PIONIER. We thank the European Commission for the support through a Marie Curie Individual Research Fellowship (to S.C). The authors thank T. L. M. Maesen, R. Krishna, T. J. H. Vlugt, D. Dubbeldam, E. J. Meier, R. Lobo, and T. Gardner for useful discussions and M. Schenk, A. Pijpelink, J. Wichers-Hoeth, and J. Heuft for endless computer support.

\section{References and Notes}

(1) Vitale, G.; Bull, L. M.; Morris, R. E.; Cheetham, A. K.; Toby, B. H.; Coe, C. G.; MacDougall, J. E. J. Phvs. Chem. 1995, 99, 16087.

(2) Lachet, V.; Boutin, A.; Tavitian, B.; Fuchs, A. H. Faradav Discuss. 1997, 106, 307 7727.

(3) Krishna, R.; Smit, B.; Vlugt, T. J. H. J.Phvs. Chem. A 1998, 102,

(4) Mellot, C. F.; Cheetham, A. K.; Harms, S.; Savitz, S.; Gorte, R. J.; Myers, A. L. J. Am. Chem. Soc. 1998, 120, 5788.

(5) Macedonia, M. D.; Maginn, E. J. Mol. Phvs. 1999, 96, 1375

(6) Schenk, M.; Vidal, S. L.; Vlugt, T. J. H.; Smit, B.; Krishna, R. Langmuir 2001, 17, 1558.

(7) Calero, S.; Smit, B.; Krishna, R. Phvs. Chem. Chem. Phys. 2001 3,4390 .

(8) Calero, S.; Smit, B.; Krishna, R. J. Catal. 2001, 202, 395.

(9) Meier, W. M. Z. Kristallogr. 1961, 115, 439.

(10) Olson, D. H.; Kokotailo, G. T.; Lawton, S. L.; Meier, W. M. J. Phvs. Chem. 1981, 85, 2238.

(11) van Koningsveld, H.; van Bekkum, H.; Jansen, J. C. Acto Crvstallogr. B43 1987, 127.

(12) Flanigen, E. M.; Bennet, J. M.; Grose, J. M.; Cohen, R. W.; Patton, J. P.; Kirchen, R. L.; Smith, R. M. Nature 1978, 271, 512.

(13) International Zeolite Association, Structure Commission, http:// www.iza-structure.org.

(14) Auerbach, S. M.; Kärger, J.; Vasenkov, S. Diffusion in zeolites. In Handbook of Zeolite Catalysis and Microporous Materials; Auerbach, S. M., Carrado, K. A., Dutta, P. K., Eds.; Marcel Dekker Inc.: New York, in press.

(15) Bates, S. P.; van Well, W. J. M.; van Santen, R. A.; Smit, B. $\underline{J}$ Am. Chem. Soc. 1996, 118, 6753. Bates, S. P.; van Well, W. J. M.; van Santen, R. A.; Smit, B. J. Phvs. Chem. 1996, 100, 17573.

(16) Satterfield, C. N.; Frabetti, A. J., Jr. AIChE J. 1967, 13, 731

(17) Choudhary, V. R.; Mayadevi, S.; Singh, A. P. J. Chem. Soc. Faradav Trans. 1995, 91, 2935.

(18) Macedonia, M. D.; Moore, D. D.; Maginn, E. J.; Olken, M. M. Langmuir 2000, 16, 3823.

(19) Calleja, G.; Pau, J.; Callas, J. A. J. Chem. Eng. Data 1998, 43, 944 
(20) Dandekar, H. W.; Funk, G. A.; Zinnen, H. A. U.S. Pat. 6,069,289 to UOP, Inc., 2000.

(21) Denayer, J. F.; Baron, G. V.; Martens, J. A.; Jacobs, P. A. J. Phys. Chem. B 1998, 102, 3077.

(22) Yan, Y. H.; Tsapatsis, M.; Gavalas, G. R.; Davis, M. E. J. Chem. Soc. Chem. Commun. 1995, 227.

(23) Vroon, Z. A. E. P.; Keizer, K.; Gilde, M. J.; Verweij, H.; Burggraaf, A. J. J. Membr. Sci. 1996, 113, 293.

(24) Coronas, J.; Noble, R. D.; Falconer, J. L. Ind. Eng. Chem. Res. 1998, 37,166

(25) Krishna, R.: Smit, B.; Calero, S. Chem. Soc. Rev. 2002, 31, 185

(26) Tuan, V. A.; Falconer, J. L.; Noble, R. D. Microporous and Mesoporous Mater. 2000, 41, 269.

(27) Ciavarella, P.; Moueddeb, H.; Miachon, S.; Fiaty, K.; Dalmon, J. A. Catal. Today 2000, 56, 253.

(28) van de Graaf, J. M. Ph.D. Thesis, Technical University of Delft, 1999.

(29) Stave, M. S.; Nicholas, J. B. J. Phys. Chem. 1995, 99, 15046.

(30) Alvarado-Swaisgood, A. E.; Barr, M. K.; Hay, P. J.; Redondo, A. J. Phvs. Chem. 1991, 95, 10031.

(31) Ryckaert, J. P.; Bellemans, A. Faraday Discuss. Chem. Soc. 1978, $66,95$.

(32) Siepmann, J. I.; Martin, M. G.; Mundy, C. J.; Klein, M. L. Mol. Phys. 1997, 90, 687.

(33) Bezus, A. G.; Kiselev, A. V.; Lopatkin, A. A.; Du, P. Q. J. Chem. Soc., Faraday Trans. 2 1978, 74, 367.

(34) Kiselev, A. V.; Lopatkin, A. A.; Shulga, A. A. Zeolites 1985, 5, 261 .

(35) Vlugt, T. J. H.; Krishna, R.; Smit, B. J. Phys. Chem. B 1999, 103, 1102.

(36) Demontis, P.; Suffritti, G. B.Chem. Rev. 1997, 97, 2845.

(37) Vlugt, T. J. H. Personal communications.

(38) Frenkel, D.; Smit, B. Understanding Molecular Simulations: From Algorithms to Applications, 2nd ed.; Academic Press: San Diego, CA, 2002.
(39) Smit, B.; den Ouden, C. J. J. J. Phys. Chem. 1988, 92, 7169.

(40) Nivarthi, S. S.; van Tassel, P. R.; Davis, H. T.; McCormick, A. V. Zeolites 1995, 115, 40. Nivarthi, S. S.; van Tassel, P. R.; Davis, H. T.; McCormick, A. V. J. Chem. Phys. 1995, 103, 3029.

(41) Lee, S. H.; Moon, G. K.; Choi, S. G.; Kim, H. S. J. Phys. Chem 1994, 98, 1561.

(42) Smirnov, K.; LeMaire, M.; Bremad, C.; Bougeard, D. Chem. Phys. 1994, 179, 445 .

(43) Mellot, C. F.; Davidson, A. M.; Eckert, J.; Cheetham, A. K. J. Phys. Chem. B 1998, 102, 2530.

(44) Auerbach, S. M.; Bull, L. M.; Henson, N. J.; Metiu, H. I.; Cheetham,

A. K. J. Phys. Chem. 1996, 100, 5923.

(45) Krause, K.; Geidel, E.; Kinder, J.; Forster, H.; Smirnov, K. S. Vibr. Spectrosc. 1996, 12, 45.

(46) Schrimpf, G.; Schlenkrich, M.; Brickmann, J. J. Phys. Chem. 1992 96,7404 .

(47) Vitale, G.; Mellot, C. F.; Bull, L. M.; Cheetham, A. K. J. Phys. Chem. B 1997, 101, 4559.

(48) Jaramillo, E.; Auerbach, S. M. J. Phys. Chem. B 1999, 103, 9589.

(49) Herrero, C. P.; Ramirez, R. J. Phys. Chem. 1992, 96, 2246.

(50) Myers, A. L.; Calles, J.; Calleja, G. Adsorption 1997, 3, 107.

(51) Talu, O.; Myers, A. L. AIChE J. 2001, 47, 1160.

(52) Buttefey, S.; Boutin, A.; Mellot-Draznieks, C.; Fuchs, A. H. J. Phvs. Chem. B 2001, 105, 9569.

(53) Soukoulis, C. M. J. Phys. Chem. 1984, 88, 4898

(54) Ricchiardi, G.; Newsam, J. M. J. Phys. Chem. B 1997, 101, 9943.

(55) Schroeder, K. P.; Sauer, J. J. Phys. Chem. 1993, 97, 6579.

(56) Maurin, G.; Senet, P.; Devautour, S.; Gaveau, P.; Henn, F.; van Doren, V. E.; Giuntini, J. C. J. Phys. Chem. B 2002, 105, 9157.

(57) Xu, Q.; Eguchi, T.; Nakayama, H.; Nakamura, N. J. Chem. Soc.. Faraday Trans. 1996, 92, 1039.

(58) Du, Z. M.; Manos, G.; Vlugt, T. J. H.; Smit, B. AIChE J. 1998 44, 1756 . 